\title{
World Journal of Postoperative complications of
Pediatric Surgery umbilical loop colostomy for anorectal malformations in neonates compared with the conventional abdominal stoma: a non-randomized study
}

Tatsuma Sakaguchi, Yoshinori Hamada, Takeshi Shirai, Hiroshi Hamada, Yusuke Shigeta, Yusuke Nakamura, Takashi Doi

To cite: Sakaguchi T, Hamada Y, Shirai T, et al. Postoperative complications of umbilical loop colostomy for anorectal malformations in neonates compared with the conventional abdominal stoma: a nonrandomized study. World $\mathrm{Jnl}$ Ped Surgery 2019;2:e000031. doi:10.1136/wjps-2018-000031

Received 23 December 2018 Revised 4 February 2019 Accepted 5 February 2019

\section{Check for updates}

(C) Author(s) (or their employer(s)) 2019. Re-use permitted under CC BY-NC. No commercial re-use. See rights and permissions. Published by BMJ.

Department of Surgery, Kansai Medical University, Osaka, Japan

Correspondence to SakaguchiTatsuma; sakaguct@ hirakata.kmu.ac.jp

\section{ABSTRACT}

Background We previously reported a pilot study of temporary umbilical loop colostomy for neonates with intermediate-type anorectal malformations (ARM) and recommended this technique because of its cosmetic excellence. We herein report the postoperative complications of umbilical stomas (US) compared with traditional abdominal stomas (AS).

Methods From our institutional prospective database, we analyzed the patients with ARMs who underwent stoma creation at Kansai Medical University Hospital from January 1995 to November 2016. The surgical technique used to create the US had been performed since 2004.

Results US and AS were made for 12 and 27 patients with ARMs, respectively. The postoperative complication rates in patients who underwent US and AS had no significant difference $(17 \%$ and $11 \%, p=0.6)$. The complications comprised a wound infection (one case of US), ileus (one case each of US and AS), mucosal prolapse (one case of AS), and depression (one case of AS). No emergency surgery was required for these complications.

Conclusion For patients with ARMs, the umbilicus appears to be a safe alternative site for temporary loop colostomy.

\section{INTRODUCTION}

The conventional abdominal stoma (AS) leaves an extra and often unattractive scar in the right or left lower abdomen. Cameron and $\mathrm{Lau}^{1}$ reported the umbilicus as a site for temporary colostomy, and Fitzgerald et $a l^{2}$ reviewed 47 cases of umbilical stomas (US) among infants and older children undergoing enterostomies. They recommended using the umbilical site for a temporary stoma in light of its cosmetic excellence and better application of ostomy appliances. Recent advances in the umbilical approach have enabled its use in the surgical treatment of various neonatal diseases, and use of this approach is considered to be a feasible and safe procedure with excellent cosmetic outcomes. ${ }^{3}$ Sauer et $a l^{4}$ created an umbilical loop stoma as a preliminary procedure for complicated Hirschsprung's disease. They recommended the method because it has the same advantages as the laparoscopic approach; that is, clear visualization of the bowel, excellent cosmetic results, a short hospital stay, little postoperative pain, early return to bowel function, and early enteral feeding. However, US are still not widely used. ${ }^{5}$ Precise data regarding their complications are required.

We previously reported a pilot study of temporary umbilical loop colostomy for neonates with intermediate-type anorectal malformations (ARM) and recommended this technique for the following reasons: minimal surgical complications, secure attachment of the stoma bag, easy stoma care, excellent appearance of the umbilicus, and no other abdominal wound. ${ }^{6}$ We herein report the postoperative complications of US compared with those of AS.

\section{PATIENTS AND METHODS}

\section{Patients}

From a prospective clinical database at Kansai Medical University Hospital, Department of Pediatric Surgery, we analyzed the patients with ARMs who underwent stoma creation from January 1995 to November 2016. The surgical technique of US creation had been performed since 2004. All surgeries were performed after obtaining informed consent from the patients.

\section{Surgical technique for US}

The surgical technique for US has been described elsewhere. ${ }^{6}$ Briefly, the skin, 


\begin{tabular}{|c|c|c|c|c|}
\hline & $\begin{array}{l}\text { Total number } \\
\text { of patients } \\
\text { ( } n=39 \text { ) }\end{array}$ & $\begin{array}{l}\text { US number } \\
\text { of patients } \\
(n=12)\end{array}$ & $\begin{array}{l}\text { AS number } \\
\text { of patients } \\
\text { ( } n=27 \text { ) }\end{array}$ & $P$ value \\
\hline \multicolumn{5}{|l|}{ Sex } \\
\hline Male & 21 (54\%) & $6(50 \%)$ & $15(56 \%)$ & 0.7 \\
\hline Female & $18(46 \%)$ & $6(50 \%)$ & $12(44 \%)$ & \\
\hline \multicolumn{5}{|c|}{ Birth weight (g) } \\
\hline $1500-2500$ & $4(10 \%)$ & $1(8 \%)$ & $3(11 \%)$ & 0.8 \\
\hline$>2500$ & 35 (90\%) & $11(92 \%)$ & 24 (89\%) & \\
\hline \multicolumn{5}{|l|}{ Stoma site } \\
\hline $\begin{array}{l}\text { Transverse } \\
\text { colon }\end{array}$ & 21 (54\%) & $7(58 \%)$ & $14(52 \%)$ & 0.7 \\
\hline $\begin{array}{l}\text { Sigmoid } \\
\text { colon }\end{array}$ & $18(46 \%)$ & $5(42 \%)$ & $13(48 \%)$ & \\
\hline
\end{tabular}

subcutaneous tissue, and fascia were vertically cored out at the base of the umbilical cord, and the umbilical vessels and urachal remnant were individually ligated. A loop stoma was created in a double-barreled fashion. The loop was divided 7 days postoperatively, and diversion of the oral bowel was completed.

\section{Statistical analysis}

Univariate analysis was performed using the $\chi^{2}$ test, and $p$ values $<0.05$ were considered statistically significant.

\section{RESULTS}

US and AS were made for 12 and 27 patients, respectively. The patients' characteristics are shown in table 1 . The ratios of sex, birth weight, and stoma site between patients in the US and AS groups were not significantly different.

The postoperative complication rates in the US and AS groups were $17 \%$ and $11 \%$, respectively $(\mathrm{p}=0.6)$. Complications occurred almost equally among the listed stoma features. Symptoms of complications comprised a wound infection (one case of US), ileus (one case each of US and
AS), mucosal prolapse (one case of AS), and depression (one case of AS). These complications did not require emergency surgeries.

Two representative cases of complicated US are described below.

Case 1: A female neonate diagnosed with Kabuki make-up syndrome and accompanying intermediate-type ARMs underwent creation of a transverse colostomy at the umbilicus 11 days after birth. Intestinal malrotation and a hiatal hernia were also present. She underwent a second laparotomy for treatment of ileus at 3 months of age. The surgical diagnosis was adhesive obstruction of the small bowel. The stoma was closed after 8 months. She also had persistent diarrhea and unclassifiable immunodeficiency.

Case 2: A male neonate with intermediate-type ARMs underwent creation of a sigmoid colostomy at the umbilicus 1 day after birth. He underwent surgical repair at 5 months of age and stoma closure at 7 months. After closure, he developed a wound infection at the umbilicus, which was cured in a few weeks by simple open drainage.

\section{DISCUSSION}

In this study, we have reported the results of 12 US compared with $27 \mathrm{AS}$ in neonates with ARMs, focusing on their complications. Our results suggest that the umbilicus is acceptable as an alternative site for temporary colostomy for patients with ARMs because the complications were limited and curable. A limitation of this study is the lack of randomization. The patients underwent operations in different periods of time; the US were performed from 2004 to 2016, while the AS were performed from 1995 to 2016. Our analysis was limited to colostomies for ARMs, and $90 \%$ of our patients had a normal birth weight. Necrotizing enterocolitis or other sepsis-related diseases were not included because their

\begin{tabular}{|c|c|c|c|c|}
\hline & $\begin{array}{l}\text { Total number of } \\
\text { complications } \\
(\mathrm{n}=5)\end{array}$ & $\begin{array}{l}\text { US number of } \\
\text { complications } \\
(n=2)\end{array}$ & $\begin{array}{l}\text { AS number of } \\
\text { complications } \\
(n=3)\end{array}$ & $P$ value \\
\hline \multicolumn{5}{|l|}{ Birth weight (g) } \\
\hline 1500-2500 & 2 (40\%) & $1(50 \%)$ & $1(33 \%)$ & 0.7 \\
\hline$>2500$ & $3(60 \%)$ & $1(50 \%)$ & $2(67 \%)$ & \\
\hline \multicolumn{5}{|l|}{ Stoma site } \\
\hline Transverse colon & $2(40 \%)$ & $1(50 \%)$ & $1(33 \%)$ & 0.7 \\
\hline Sigmoid colon & $3(60 \%)$ & $1(50 \%)$ & $2(67 \%)$ & \\
\hline \multicolumn{5}{|l|}{ Symptoms } \\
\hline Wound infection & $1(20 \%)$ & $1(50 \%)$ & 0 & 0.3 \\
\hline Ileus & $2(40 \%)$ & $1(50 \%)$ & $1(33 \%)$ & 0.7 \\
\hline Prolapse & $1(20 \%)$ & 0 & 1 (33\%) & 0.4 \\
\hline Depression & $1(20 \%)$ & 0 & 1 (33\%) & 0.4 \\
\hline
\end{tabular}

AS, abdominal stoma; US, umbilical stoma. 
complication rates are remarkably increased regardless of the stoma location. A US would not be recommended for neonates with a life-threatening disease such as perforated necrotizing enterocolitis because although its use is temporary, its utmost purpose is lifelong cosmesis. One may argue that there is a high risk of wound infection at the umbilicus. Yang et $a l^{7}$ reported that among 20 patients with high ARMs, they did not encounter umbilical wound infection after successful transumbilical colostomy following laparoscopic-assisted anorectoplasty. We experienced one case of umbilical wound infection that was cured by simple open drainage.

\section{CONCLUSION}

Our results suggest that the umbilicus is acceptable as an alternative site for temporary colostomy in patients with ARMs.

Contributors TS wrote the major part of the manuscript. YH and TD were both mentors to create umbilical stoma, and planned the study. TS, HH and YS assisted surgeries and extracted data. YN conducted statistical analysis.

Funding This study was supported by the research fund of the Department of Surgery of Kansai Medical University.

Competing interests None declared.

Patient consent for publication Not required.
Ethics approval This study was performed in accordance with 'Kansai Medical University Policy Concerning the Maintenance of High Ethical Standards in Research and Other Scholarly Activities'.

Provenance and peer review Not commissioned; externally peer reviewed.

Open access This is an open access article distributed in accordance with the Creative Commons Attribution Non Commercial (CC BY-NC 4.0) license, which permits others to distribute, remix, adapt, build upon this work non-commercially, and license their derivative works on different terms, provided the original work is properly cited, appropriate credit is given, any changes made indicated, and the use is non-commercial. See: http://creativecommons.org/licenses/by-nc/4.0/.

\section{REFERENCES}

1. Cameron GS, Lau GY. The umbilicus as a site for temporary colostomy in infants. J Pediatr Surg 1982;17:362-4.

2. Fitzgerald PG, Lau GY, Cameron GS. Use of the umbilical site for temporary ostomy: review of 47 cases. J Pediatr Surg 1989;24.

3. Soutter AD, Askew AA. Transumbilical laparotomy in infants: a novel approach for a wide variety of surgical disease. J Pediatr Surg 2003;38:950-2.

4. Sauer CJE, Langer JC, Wales PW. The versatility of the umbilical incision in the management of Hirschsprung's disease. J Pediatr Surg 2005;40:385-9.

5. Raj P, Kumar Sarin Y. Umbilicus: a site for stoma in Hirschsprung's disease. J Neonatal Surg 2015;4.

6. Hamada Y, Takada K, Nakamura Y, et al. Temporary umbilical loop colostomy for anorectal malformations. Pediatr Surg Int 2012;28:1133-6.

7. Yang L, Tang S-T, Li S, et al. Two-stage laparoscopic approaches for high anorectal malformation: transumbilical colostomy and anorectoplasty. J Pediatr Surg 2014;49:1631-4. 